\title{
ANTI BREAK - OUT SYSTEM FOR CONTINOUSES CASTING MACHINE IN INDUSTRY 4.0
}

\author{
Miroslav KLUS, Ondřej KOZINSKI, Petra SVOBODOVÁ, Antonín TOMEČEK \\ ${ }^{1}$ VSB - Technical University of Ostrava, Ostrava, Czech Republic, EU, \\ miroslav.klus.st@vsb.cz,ondrej.kozinski@vsb.cz,petra.svobodova@vsb.cz, antonin.tomecek.st@vsb.cz
}

\author{
https://doi.org/10.37904/metal.2021.4279
}

\begin{abstract}
The changing face of industry is increasingly loading automation. The fourth industrial revolution is a sign for the current trend of modernization and automation of individual workplaces and equipment. As part of the modernization of the continuous casting machine No. 1 (ZPO1) of Trinecké železárny, a. s., (TŽ), the electromechanical oscillating mechanism has been recently replaced by a modern hydraulic oscillating mechanism from Danieli. However, due to the implemented modernization interventions, it was necessary to address other important aspects associated with the control of continuous casting technology, such as the functionality of anti-breakout system (so-called DGS) which was based in 2000 on the analysis of a digital signal from the cardan shaft to change the time shifts of the frequency of the oscillating mechanism. This signal, by switching to the new hydraulic cylinder drive technology, was no longer available for calculation in breakout prediction system, and therefore it was necessary to develop a new way of evaluating the breakout alarm called ABS. At the same time, however, new possibilities have emerged to further develop the continuous casting management process to meet the requirements of the Industry 4.0 concept. The new prediction system is currently based on friction force change in hydraulic cylinder. Friction coefficient is directly calculated, from analogue signals coming from hydraulic oscillation machine. The evaluation criteria are automatically set according to steel grades.
\end{abstract}

Keywords: Antibreak-out system, continuous casting, mold

\section{INTRODUCTION}

In recent years, emphasis has been placed on predictive maintenance to optimize production efficiency and reduce production downtime. Accurate and forward-looking information on the possible occurrence of a fault condition can prevent economic losses and non-compliance with the production plan. In the past, a frequent phenomenon of production losses in the operation of continuous casting of steel number 1 (ZPO1) was a breakout in the casting stream. Due to the rupture of the casting crust, this phenomenon causes the given casting stream to be stopped, for the duration of the refilling of the currently cast sequence and possible downtime in production for work related to removing steel spatter in the casting arc and replacing damaged casting units [1]. In 2000, an anti-breakout system (so-called DGS) was developed and installed for the given continuous casting equipment to predict the risk of rupture of the casting crust. This diagnostic system worked by analyzing the data available from the accelerometer installed on the arm of the oscillating mechanism and the digital signal from the engine gimbal. Special algorithms were designed, which calculated on the basis of a change in the frequency of individual alarm signals indicating the danger of the formation of significant cracks (see Figure 1), which could lead to the initiation of rupture of the casting crust [2].

Another added value of the DGS system was the diagnostic system evaluating the condition of the oscillating mechanism and the deviations caused by a poorly seated casting unit. Although the original anti-breakout system was fully functional and fully suitable for the continuous casting equipment, it was necessary to start developing its new concept, as the original electromechanical oscillation was replaced by a modern hydraulic 
drive, which lost the signal from the cardan of the electromechanical motor [3]. The functionality of the DGS system is absolutely crucial. Decisions to replace the existing oscillation mechanism with a new one were based on the fact that hydraulic oscillation provides much wider and more flexible options for optimizing meniscus events, as (unlike electromechanical oscillation) it allows to change the crystallizer stroke in any casting period. set ideal conditions for the given steel for the formation of oscillating wrinkles, compression of the casting crust and lubrication at any casting speed and thus optimize the processes taking place in the meniscus area, which are schematically shown in (see Figure 2). Proper adjustment of the hydraulic oscillation also makes it possible to minimize the risk of rupture of the casting crust, however, such adjustment usually goes against quality requirements, so it is always necessary to find some compromise taking into account quality and safety risks depending on the cast quality and format. It was thus necessary to find ways to newly detect risk conditions, but also to diagnose the state of the entire oscillating mechanism [4] [5]. This challenge thus provided the potential of the current practice of continuous casting process control to be further shifted to a concept compatible with the requirements of Industry 4.0 [6].

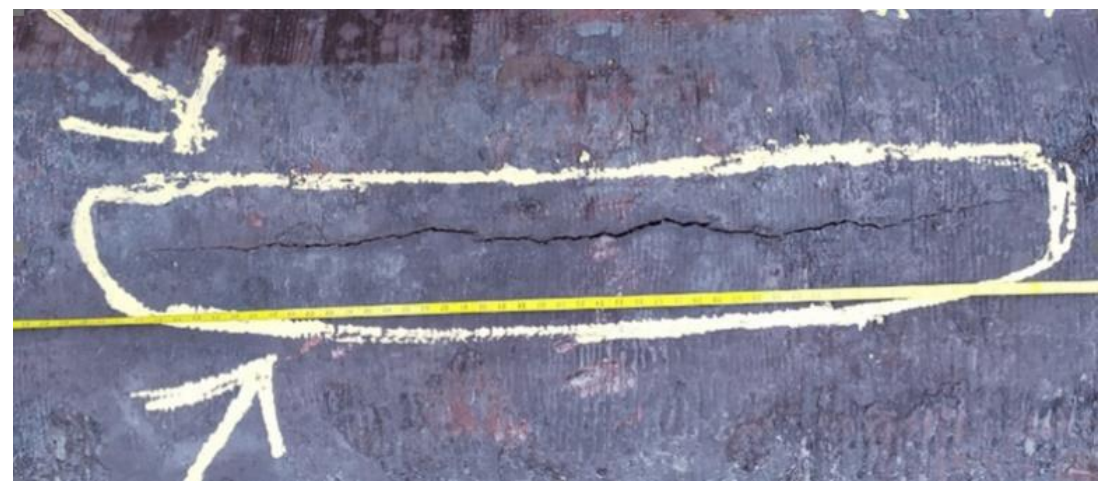

Figure 1 Example of a bloom surface crack causing strand break-out. Source: [6]

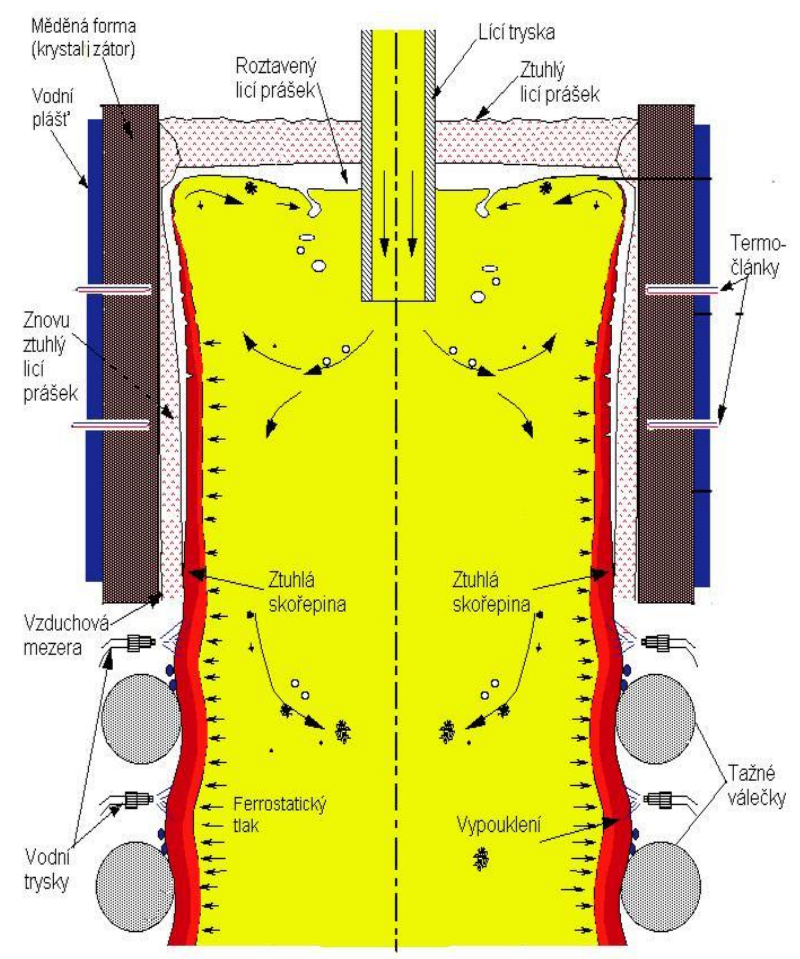

Figure 2 Typical processes in the mould. Source: [6] 


\section{NEW ALGORITHM FROM BREAKOUT EVALUTION}

\section{Calculation of the coefficient of friction}

By analyzing the signals in the Simatic S7 control system, which controls the movement of the hydraulic cylinder of the oscillating mechanism, suitable analog signals were found for the development of a new algorithm for breakout prediction. The basic essential signal is the coefficient of friction, which expresses the force exerted by the steel on the walls of the crystallizer and what resistance arises due to friction during the movement of the preform in the crystallizer. The coefficient of friction is calculated as the difference between the load of the hydraulic cylinder by the oscillation of the crystallizer at no load and the load during the actual casting. Calculations are performed independently for each cylinder. The individual analog signals for the calculation are read from the Sinamics inverter oscillating mechanism, which controls the hydraulic cylinder motor. To calculate the coefficient of friction, it is first necessary to determine the work of the hydraulic cylinder during real casting and during idle operation. The operation of the hydraulic cylinder of the oscillating mechanism of the crystallizer during casting is given by the following equation:

$W_{\text {hot }}=\oint_{\text {cicle }}(F \cdot d y)$

where:

$$
\begin{aligned}
& W_{\text {hot }} \text { - work under load, in }(\mathrm{kN} \cdot \mathrm{m}) \\
& d y \text { - the final stroke of the oscillations of the crystallizer }(\mathrm{m}) \\
& \boldsymbol{F} \text { - the measured value of the force acting on the cylinder }(\mathrm{kN}) \text {. }
\end{aligned}
$$

The work of the hydraulic cylinder of the oscillating mechanism of the crystallizer on the void outside the casting is then determined analogously by the equation:

$W_{\text {cold }}=\oint_{\text {cicle }}(F \cdot d y)$

In the next phase, it is necessary to determine their curves (so-called working curves) depending on the total stroke of the hydraulic cylinder $s(\mathrm{~mm})$ and the frequency of oscillations $f\left(\mathrm{~s}^{-1}\right)$, ie for off-load operation it is a dependence:

$W_{\text {cold }}=W_{\text {cold }}(s, f)$

It is necessary to have different working curves drawn for all (sinusoidal) asymmetric conditions, from which the friction analysis is based. In real casting, the work of the hydraulic cylinder is fundamentally affected by the events in the crystallizer, which causes a significant deformation of the operating curves common to the idle mode, and the nature of the detected changes is the key to estimating friction in the crystallizer. During casting, the preform shrinks, and the effect of the lubricant impairs heat transfer and even heats the crust. The crust bends back to the crystallizer plate due to the ferrostatic pressure. Liquid steel re-penetrates into the cracks formed in the layer of already solidified dendritic crystals. Only in the lower part of the crystallizer is the crust strong enough to maintain the ferrostatic pressure and the gap between the crust and the crystallizer plate, which has fallen out of the solidified casting powder, is filled with gas. All these events then significantly change the friction in the crystallizer, and thus the working curves of the cylinder.

Based on the knowledge of the working curves of the hydraulic oscillation cylinder, it is then possible to determine the friction force tfric, which is calculated as the working average force divided by the surface area of the crystallizer $\left(\mathrm{kN} \cdot \mathrm{m}^{-2}\right)$, ie it is given by the equation: 


$$
\tau_{\text {fric }}=\frac{W_{\text {hot }}-W_{\text {cold }}}{2 \cdot s \cdot(\text { Mwidth }+ \text { Mthickness }) \cdot L_{\text {act }}}
$$

where:

$$
\begin{aligned}
& \text { Mwidth - the width of the crystallizer }(\mathrm{m}) \\
& \text { Mthickness - the thickness of the crystallizer }(\mathrm{m}) \\
& L_{\text {act }} \text { - the actual effective length }(\mathrm{m})
\end{aligned}
$$

The coefficient of friction is defined as the ratio of the friction force to the ferrostatic force in the crystallizer, ie it is given by the equation:

$\mu_{\text {fric }}=\frac{2 \cdot \tau_{\text {fric }}}{\rho \cdot g \cdot L_{a c t}}$

where:

$$
\begin{aligned}
& \rho \text { - the density of liquid steel }=70400 \mathrm{kN} \cdot \mathrm{m}^{-3} \\
& g-\text { the gravitational acceleration }=9.81 \mathrm{~m} \cdot \mathrm{s}^{-2}
\end{aligned}
$$

For analysis, all the above variables are constantly recorded in the In Touch visualization software from Siemens in the operator's cab. Individual signals are stored in the diagnostic software only. The system only serves for the collection and analysis of process data composed of perfectly modified hardware and software components for the processing of measured data. The only advantage of the software is the retrospective analysis of the course of individual curves and possible fault diagnosis. Last but not least, a great advantage is the possibility of analyzing the dependence of individual signals on each other and possible assistance in predicting the fault state of the device.

\section{Algorithm for calculating the storm prediction alarm}

During the design of the evaluation algorithm, in the first phase there was a systematic collection of data and their confrontation with the records of the output control of continuously cast billets. The analysis showed that the coefficient of friction $\mu$ fric is a very effective indicator of non-standard processes in the crystallizer, which can lead to a of rupture of the casting crust. Figure 3 shows an example of a risk increase in the coefficient of friction. However, for the new ABS anti-breakout system to work properly, it was necessary to determine critical increases in the coefficient of friction, which can vary significantly for different qualities and formats. Each steel has different typical characteristics during casting, when for example low-carbon (especially peritectic) steels on the one hand there is a very sharp and often irregular shrinkage of the casting crust, on the other hand their meniscus is very strong and there is no great risk of sticking. to the crystallizer wall. On the other hand, steels with a higher carbon content are characterized by a high susceptibility of the meniscus to stick to the crystallizer wall, because the meniscus is very soft and therefore very willing to attract to the crystallizer wall, especially during positive strip periods, when negative pressure is formed between the meniscus. Thus, during the casting of different groups of steels, different movements in the coefficient of friction occur, and the individual increases can represent either the normal manifestations given by the characteristic behavior of the steel during solidification or, conversely, the risk of breakout. It is therefore appropriate to always carefully consider what the individual peaks in the trend of the coefficient of friction mean and to interpret them correctly in the analysis.

Currently, 3 levels of critical increases in the coefficient of friction are defined at ZPO1 in TŽ, which are also monitored for different brands in different time windows. The set criteria are automatically read in the control system for individual steel brands and confronted with the real curves of the friction coefficient during 
continuous casting with the new anti-breakout ABS system. When the limit states are exceeded, the ABS antibreakout system generates adequate interventions in the casting process, effectively preventing the occurrence of rupture of the casting crust. Without the necessary assistance of the crew.

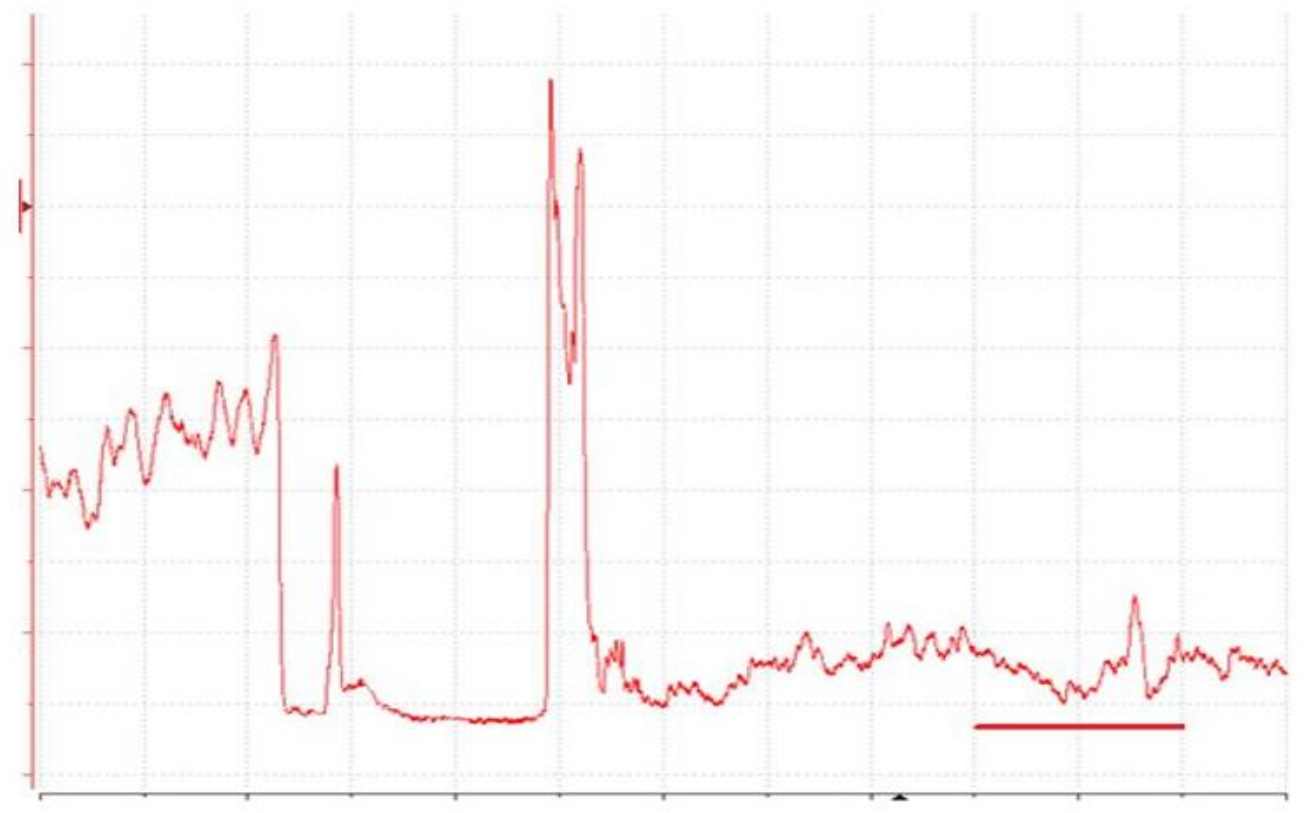

Figure 3 Trend of change in the coefficient of during continuous casting. Source: (own)

\section{CONCLUSION}

Under the conditions of continuous casting equipment number 1, a new anti-breakout ABS system was developed, based on the analysis of the load on the hydraulic oscillation cylinders. The coefficient of friction, which is calculated on the basis of the analysis of the working curves of the cylinder in the unloaded state and during casting, has proved to be a suitable indicator of risk conditions during continuous casting. It has also been shown that for the correct function of the proposed anti-breakout system, it is necessary to use different critical increases in the coefficient of friction and monitor them in different time windows. The need to use different permissible increases in the coefficient of friction for different grades (as well as formats) in different time windows results from different manifestations of individual steels during solidification, with some marks showing high and irregular shrinkage, others prone to sticking to the crystallizer wall. movements of the coefficient of friction during casting, which are not directly related to the increasing risk of rupture of the casting crust. Currently, a total of 3 levels of critical increases in the coefficient of friction are used on ZPO1, which are also monitored for individual brands in different time windows. In addition, the developed ABS anti-breakout system makes it possible to automatically generate adequate interventions in the casting process and thus effectively prevent of rupture of the casting crust, without the need for crew assistance, which is in line with modern requirements for compliance with Industry 4.0 principles. Currently, work is also underway on the further development of the already developed and fully functional ABS system, when in cooperation with VUHŽ Dobrá we managed to test a new three-axis digital accelerometer, the implementation of which will further refine the detection of hazardous conditions and diagnose the entire oscillating mechanism.

\section{ACKNOWLEDGEMENTS}

The work was supported by the specific university research of Ministry of Education, Youth and Sports of the Czech Republic No. SP2021/71 and SP2021/23. 


\section{REFERENCES}

[1] BECKMAN, J. Optimálné metody údržby: Praktická príručka. Bratislava: Alfa, 1990. ISBN 80-05-00657-8.

[2] BÖHM, Z., CAGAŠ, J., DOLEJŠí, Z., KUČERA, J., PĚTROŠ, J., ŠMRHA, L. Plynulé odlévání oceli. Praha: SNTL Nakladatelství technické literatury, 1992, p. 448. ISBN 80-03-00661-9.

[3] DAVID, J. et al. Etapa 5 - Zvyšování kvality plynule litých předlitků monitorováním a diagnostikováním vad v závislosti na životnosti desek krystalizátoru. VŠB-TU Ostrava, 2011, p. 25.

[4] IRVING, W. R. Continuous casting of steel. Institute of Materials. 1993. ISBN 0901716537, 9780901716538.

[5] Proteus Industries Inc. Different Kinds of Liquid Flow Meters: Measuring the Fluid Flow in Diverse Ways [online]. 2017. [viewed: 2019-11-03] Available from: https://proteusind.com/different-kinds-of-liquid-flow-meters/

[6] ŠTĚTINA, J. Optimalizace parametrů lití sochorů pomocí modelu teplotního pole. Habilitační práce. VSB-TU Ostrava. 2008. [viewed: 2017-02-25]. Available from: http://ottp.fme.vutbr.cz/users/stetina/habilitace/kapitola$\underline{1 . h t m}$ 